\title{
EVALUATING VISUAL ELEMENTS IN TWO EFL TEXTBOOKS
}

\author{
Ali Roohani \\ Mohammad Sharifi \\ Shahrekord University, Iran \\ email: roohani.ali@gmail.com, sharifimohammad66@gmail.com
}

Article received: 28 December 2013

Final proof received: 11 December 2014

\begin{abstract}
This study evaluates visual elements in two English textbooks, that is, Interchange 3 and Top Notch $3 B$, commonly taught to Iranian EFL learners; it analyzes illustrations to find out the balance of black-and-white and color drawings and photos and examines the extent to which visual materials are used for decorative purposes. The analysis of visual elements reveals that, first, color pictures constitute a large percentage of illustrations in both textbooks, reflecting current publication trend for stylish color pages. Second, Interchange 3 has more drawings than the Top Notch 3 whereas the Top Notch textbook has more photos, which can establish more authenticity and result in its higher price. Third, the majority of the portraits are color photos, and, further, actions are represented more through drawings than photos, presumably because of practicality issues. Finally, pictures used for decorative purposes constitute a small percentage of illustrations in both textbooks, indicating their pedagogically facilitative effects.
\end{abstract}

Keywords: Evaluation, L2 Teaching, Textbooks, Visual elements

Since the need for English language learning has been recognized in today's life, the process of creating materials for English as foreign language (EFL) has gained significance. EFL materials are defined as anything which promotes English language learning. Generally, EFL materials are divided into three kinds: 1) printed materials such as books, workbooks, or worksheets, 2) non-print materials such as cassettes, videos, or computer-based materials, and 3) materials that comprise both print and non-print sources such as materials on the Internet (Richards, 2001). Among these kinds of materials, the first and second types are crucial in English language teaching (ELT) in developing countries because they can be more accessed by the second/foreign (L2) learners in classrooms. Additionally, among printed materials, textbooks seem to be vital in language curriculum, without which many objectives of the program are hard to achieve; "no teaching-learning situation, it seems, is complete until it has its relevant textbook" (Hutchinson \& Torrers, 1994, p. 314). Textbooks are essential materials which can bring about learners' success or failure (Mukundan, Nimechisalem, \& Hajimohammadi, 2011). Therefore, the evaluation of textbooks is of utmost importance in EFL contexts.

Material evaluation is "a process that involves measuring the value of or the potential value of a set of learning materials. It involves making judgments about the effect of the materials on the people using them" (Tomlinson, 2003, p. 15). A heated argument in the area of material development and evaluation concerns the effects of visual materials or elements on L2 learning, in general, and of illustrations, in particular. Visual materials can be any visual facility such as slides used in classroom. And visual elements are considered as any visual material such as drawings, and photos included in a textbook which facilitates learning (Tomlinson, 2003). 
A potential research issue in the evaluation of ELT materials concerns the use of visual elements. It is assumed that a text with visual elements is far better comprehended in comparison with a text devoid of any visual elements (Ametller \& Pinto, 2002). Visuals can be effective if certain conditions are met. For instance, if they are used appropriately with written texts, and there exists a match between the pictures and the purpose for which they are utilized, they can be effective. When used inappropriately, as Allen (2011) points out, visuals can have adverse rather than facilitative effects, that is, they can lead to cognitive load on the part of the L2 students. Thus, it is important to see what use is made of visual elements in EFL or ELT textbooks. Given the important role of visual elements in selecting and improving the quality of textbooks (Hill, 1990; Wright \& Haleem, 1991), the current study intended to examine visual elements in two EFL/ELT textbooks.

Studying the literature on evaluating materials, one can find out that one of the main features of instructional textbooks is visual representation used to facilitate learning. Generally, visuals, which are employed for enhancing learners' language learning, can be facilities - such as flashcards, handouts, film strips, and slides-which are used by both learners and teachers in classroom. They can also be elements-such as photos and drawings - which are included in textbooks so as to facilitate language learning. These elements can be defined as any representational features of textbooks which can increase the comprehension of the contents of lessons or clarifying instructions for doing exercises and activities (Jahangard, 2007). Research has shown that they can be related to materials being learned. For instance, in an experimental study, Erfani (2012) investigated the probable effect of using visual materials on reading comprehension ability of Iranian university students. The participants, who were majoring in physics, were categorized into two experimental and control groups. In the experimental group, some passages accompanied by different kinds of pictures were taught, whereas in the control group, the same passages were taught without the pictorial context. Results showed that the experimental group who received passage furnished with pictures performed better than control group.

Evaluating ELT materials has been a concern of some researchers in the field. For instance, Hill (2003) conducted a study on the role of illustrations in ELT materials to gauge current publication trends; he analyzed images in two ELT textbooks (Cutting Edge Intermediate and Inside Out Intermediate) and categorized them as either useful or decorative. He concluded that $55 \%$ of all images in the texts were purely decorative with students not "asked to use them in any way" (p. 176). In another study, Hill (2003) examined visual elements in four British ELT textbooks (Headway Pre-Intermediate, UpperIntermediate Matters, Cutting Edge Intermediate, and Inside Out Intermediate), all published in 1990s. In this study, the researcher pursued the balance between black-and-white and color illustrations within the main texts of the four textbooks. Results showed that Headway and Matters had the highest percentage of black-andwhite and color illustrations respectively. Another study on picture analysis was conducted by Romney and Bell (2012), who analyzed Business English textbooks; they categorized pictures as either instructional or decorative. They defined images as instructional when there were written instructions included in the text for either the students or the teacher to do something with the image. It was revealed that $73 \%$ of the images in the texts were decorative, with only $27 \%$ being instructional. In Iranian EFL context, Jahangard (2007) tried to evaluate four EFL textbooks, which were used in Iranian 
senior high schools by the Ministry of Education. He used 13 criteria which were extracted from various evaluation checklists. One of the criteria was the appropriateness of visual materials. Results showed that the four textbooks had better visual features in comparison with the three other textbooks which were used before in Iranian high schools.

Evaluating visual elements in L2 textbooks is important, particularly in EFL contexts where learners have little exposure to target language. Although different books and articles (e.g., Brand, 1997; Hill, 1990; Gerrard, 2008; Porcaro, 2001; Wright \& Haleem,1991) have been written showing the significance of visual elements and literacy in ELT, there still exists little research on analysis of visual elements in ELT textbooks, particularly in Iran. Given that no study has been conducted to analyze the balance of different visual elements in ELT textbooks used in Iran, this study is an attempt to look into this issue.

\section{METHOD}

\section{Purpose of the Study}

The existence of a plethora of ELT textbook in the market makes it difficult for language teachers and course designers to decide which one is more useful in their own contexts and which one addresses their learners' needs more closely (McDonough \& Shaw 2003). Thus, a need is constantly felt to analyze our ELT textbooks to find out the suitability and usefulness of the materials in a certain context with the hope of helping L2 teachers and materials developers to modify the existing textbooks or develop more appropriate ones for L2 learners. Additionally, as Hill (2003) points out, ELT textbooks, aimed at international market for young and adult EFL learners, have moved on from the picture-free times of the past, through black-and-white drawings, to the current range of materials with stylish color drawings and state-of- the-art photographs. The current study is thus intended to examine visual elements in two internationally-marketed ELT textbooks, commonly used in language schools in Iran. More specifically, it examines the balance of illustrations, i.e. drawings and photos, by providing a profile of visual elements in the Interchange 3 and Top Notch $3 B$ textbooks. Additionally, it explores the extent to which pictures in the textbooks are used for decorative purposes since it is important to see what use is actually made of visual elements in ELT textbooks. Perhaps, ELT publishers, authors or editors provide attractive space-filling accompanying illustrations which are more decorative than pedagogically useful.

\section{Data Collection}

To probe the purpose of this study, data were collected from Interchange 3 (Richards, Hull, \& Proctor, 2005) and Top Notch $3 B$ (Saslow, \& Ascher, 2006). The two textbooks are A4 format $(21 \times 27 \mathrm{~cm})$, and both are among the most commonly-used ELT instructional textbooks in Iranian foreign language institutes. Meanwhile, both textbooks are written for upper-intermediate level students, and focus on communicative language teaching; EFL students are supposed to learn the four main English skills of listening, speaking, reading, and writing in both textbooks. Interchange 3 includes 16 units, each of which consists of several sections such as Snapshot, Conversation, Grammar Focus, Word Power, Listening, Discussion, Writing, and Reading. Top Notch $3 B$ includes 5 lessons, each of which consists of several sections such as Topic Preview, Sound Bites, Grammar Snapshots, Conversation Snapshot, Vocabulary, and Listening.

The current study used content analysis in which frequency of black-andwhite and color drawings and photos were 
obtained by two raters. As Elo and Kyngas (2008, p.107) state, "content analysis is a method of analyzing written, verbal, or visual communication messages", which can be used for texts and visuals. To find out the frequency, all sections of the textbooks (excluding the workbooks) were investigated thoroughly by the two raters. After the tabulation of the raw data, they were converted to the percentages whenever necessary. Kappa measure of agreement was run through SPSS (version 18) on the frequencies of illustrations with regard to selected categories to ensure inter-rater reliability of the collected data. The Kappa value was found to be 0.94 . As
Peat (2001) states, a Kappa value above 0.70 indicates a good agreement, hence a good measure of inter-rater consistency. The average of frequencies from the two raters was reported where they did not agree on the frequencies of collected data.

\section{FINDINGS AND DISCUSSION}

The first concern of this study was to provide a profile of illustrations in Interchange 3 and Top Notch 3B. Thus, the frequencies of black-and-white and color drawings and photos were obtained from the above-mentioned textbooks. The results are summarized in Table 1.

Table 1. The Balance of Pictures in Two Textbooks

\begin{tabular}{lcc}
\hline Properties & Interchange 3 & Top Notch B3 \\
\hline Pages of text & 111 & 59 \\
Color drawings & 141 & 42 \\
Black and white drawings & 0 & 6 \\
Total drawings & 141 & 48 \\
Color photos & 79 & 131 \\
Black and white photos & 5 & 4 \\
Total photos & 84 & 135 \\
\hline Total pictures & 225 & 183 \\
\hline
\end{tabular}

As Table 1 demonstrates, Interchange 3 has more drawings (141), including color and black-and-white ones, than Top Notch $3 B(48)$. Given the number of pages in both textbooks, the Interchange textbook has drawings about 1.27 times more than the Top Notch textbook. Besides, there is no case of black-and-white drawings in the Interchange textbook. On the other hand, Top Notch $3 B$ has more photos (135) than Interchange 3 (84). Given the smaller number of pages in Top Notch, the above data indicate that the Top Notch textbook has photos three times more than the Interchange textbook. All in all, Interchange 3 includes more pictures (225) than Top Notch $3 B$ (183), but the proportion of pictures in Top Notch is more than Interchange given the number of pages in each textbook (i.e. about 1.5 times more). Moreover, color photos and color drawings constitute a high percentage of total pictures in both textbooks. In Interchange 3 , the frequency numbers indicate that about $62 \%$ are color drawings and about $35 \%$ percent are color photos. In Top Notch $3 B$, the frequency numbers show that about $23 \%$ are color drawings and about $71 \%$ percent are color photos.

To move further, in order to see what these pictures illustrate, both color photos and color drawings were classified into five categories including portrait, place, object, interaction, and action. The results of examining color drawing and color photos on the basis of the five categories are presented in Table 2.

According to Table 2, color drawings in Interchange 3 are used more for objects (49) whereas in Top Notch 3 they are used more for actions (17). Also, color photos in Interchange 3 are used more for portraits 
(49) while in Top Notch 3 they are used more for interactions. Also, the two textbooks differ in that Interchange 3 uses more color drawings to show objects and interactions whereas Top Notch 3 uses color photos to do so. But in both textbooks, color photos are used more than color drawings to show portraits and places. Besides, in both textbooks, color drawings are used more than color photos to show actions.

Furthermore, as Table 2 displays, in the data collected from both textbooks, $25.70 \%$ show portraits, $22.65 \%$ percent show objects, $20.61 \%$ show interactions between people, $20.10 \%$ show people doing things, and places constitute the least percentage of pictures (10.94\%).

Table 2. Analysis of Color Drawings and Color Photos in Two Textbooks

$\begin{array}{llll}\text { Categories } & \text { Interchange 3 Notch } 3 & \text { Totals }\end{array}$

\begin{tabular}{lccccc}
\hline Picture & Color Drawing & Color Photo & Color Drawing & Color Photo & \\
Portrait & 24 & 35 & 8 & 34 & 101 \\
Place & 8 & 11 & 0 & 24 & 43 \\
Object & 49 & 5 & 10 & 25 & 89 \\
Interaction & 27 & 9 & 7 & 38 & 81 \\
Action & 33 & 19 & 17 & 10 & 79 \\
\hline Totals & 141 & 79 & 42 & 131 & 393 \\
\hline
\end{tabular}

Another purpose of this study was to see the extent to which the illustrations were used for decorative purposes. According to Lohr (2003), decorative visuals do not have association with instructional content; they are used to make materials more attractive, increase learners' interest in the materials or make a positive reaction to the content. To probe the above purpose, the frequencies of pictures which were allocated to use (i.e. non-decorative) and decoration (i.e. decorative) in the above-mentioned textbooks were obtained. Table 3 summarizes the relevant information and the percentages.

According to Table 3, photos are used in both Interchange $3(34.2 \%)$ and Top Notch $3(66 \%)$ more for non-decorative than decorative purposes. Likewise, drawings used in both Interchange 3 (58.2\%) and Top Notch 3 (26\%) have more non-decorative (i.e. use) functions than decorative ones. In addition, results in Table 3 indicate that a low percentage of pictures $(5.15+2.69=7.84 \%)$ are decorative. And a high percentage of pictures $(48.53+43.63=92.16 \%)$ can be regarded as non-decorative.

The results obtained from the present study indicate the Interchange 3 and Top Notch $3 B$ textbooks can gain some advantages and disadvantages. Both textbooks have used various types of photos and drawings; the incorporation of different visual elements into teaching materials to facilitate language learning 
gives an advantage to these ELT textbooks. Employing various illustrations in Interchange 3 (with average of about 2.03 per page) and Top Notch $3 B$ (with an average of about 3.10 per page) might highlight facilitative effects of illustrations. As Ametller and Pinto (2002) have argued, visual elements have an important effect on transferring knowledge; a text accompanied with visual elements is far better comprehended than a text devoid of any visual elements. Besides, students today prefer pages with color pictures than picture-free pages "because they are used to being surrounded by visual images in all areas of everyday life" (Hill, 2003, p. 177). "The $21^{\text {st }}$ century is a visual world with a visual culture" (Tiemensma, 2009, p. 1); there seems to be a shift in trend. Hill (2003) reported that in Headway (Soars \& Soars, 1991) published about two decades ago, black-and-white pictures constituted the highest percentage of illustrations. But in the above textbooks, more recently published, the proportion of color illustrations was noticeable. In addition, the use of various illustrations may engage more visually oriented students in language learning activities in classroom. This issue becomes important when we consider the finding that in the above instructional textbooks, particularly Interchange 3, less attention is devoted to black-and-white illustrations than color pictures. As Harmer (2001) argues, color visuals attract learners' attention more and appeal to more students.

Table 3. Use versus Decoration in Interchange 3 and Top Notch $3 B$

\begin{tabular}{lcccccc}
\hline \multirow{2}{*}{ Two Categories } & \multicolumn{1}{c}{ Interchange 3 } & \multicolumn{2}{c}{ Top Notch 3B } & \multicolumn{2}{c}{ Totals } \\
\cline { 2 - 7 } & $\mathbf{N}$ & $\%$ & $\mathbf{N}$ & $\%$ & $\mathbf{N}$ & $\%$ \\
\hline Photos: Decoration & 7 & 3.1 & 14 & 7.5 & 21 & 5.15 \\
Photos: Use & 77 & 34.2 & 121 & 66 & 198 & 48.53 \\
Drawings: Decoration & 10 & 4.5 & 1 & .55 & 11 & 2.69 \\
Drawings: Use & 131 & 58.2 & 47 & 26 & 178 & 43.63 \\
\hline Totals & 225 & 100 & 183 & 100 & 408 & 100 \\
\hline
\end{tabular}

Furthermore, on the positive side, a low percentage of pictures are decorative in both Interchange 3 and Top Notch $3 B$ textbooks, and illustrations are mostly used in the texts with a pedagogical function; it is assumed that the authors and publishers of these instructional textbooks are less interested in providing just attractive space-filing accompanying pictures and illustration-as-mere decoration than providing photos and drawings with activities attached to them. The results obtained in the present study is different from the results obtained by Hill (2003), who reported that the majority of illustrations in two ELT British textbooks (Cutting Edge Intermediate and Inside Out Intermediate) were purely decorative. Romney and Bell (2012), who analyzed Business English textbooks, also reported that the majority of illustrations were decorative. Although using pictures for decorative purposes is good to arouse a language learner's interest, as Hill (2003) argues, they should not be used excessively for ornamentation in lessons; rather, as Levin (1981) states, they should help students to memorize things which are difficult to remember, clarify difficult concepts or ideas, organize the information 
presented to make them easier to understand, make an abstract idea or concept more concrete, or repeat what is in the text. In both textbooks, there is much evidence of non-decorative illustrations. For instance, Figure 1, taken from Top Notch $3 B$, displays an old woman and a girl giving each other gifts. This photo helps EFL students learn or remember the meaning of giving gifts as a way to commemorate a holiday. Also, the drawing on the right shows a person who is walking on a cliff path. Through this color drawing, the concept of 'danger' is clarified and students better learn the meaning of the adjective 'dangerous'. Moreover, Figure 2, taken from Interchange 3, pictures an apartment which has some problems. Students are supposed to use the verb need with gerund and passive infinitive structures by looking at the items in the room. Through this color drawing, students practice what they had read before in the grammar section. They can have a meaningful language learning activity. Both interpretive and representational functions of these pictures reflect nondecorative use.
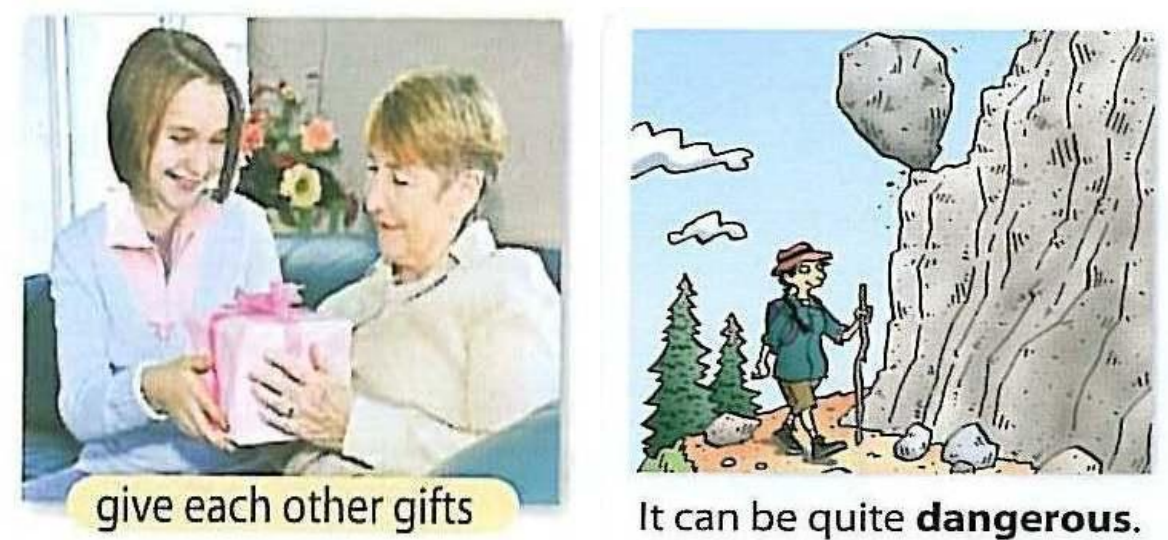

It can be quite dangerous.

Figure 1. Examples of non-decorative pictures (adopted from Top Notch 3B, pp. 76 \& 114)

A What needs to be done in this apartment? Write sentences about these items using need with gerunds or passive infinitives.

1. the walls (paint)

2. the rug (clean)

3. the windows (wash)

4. the clothes (pick up)

5. the lamp shade (replace)

6. the wastebasket (empty)

7. the ceiling fan (adjust)

8. the plant (water)
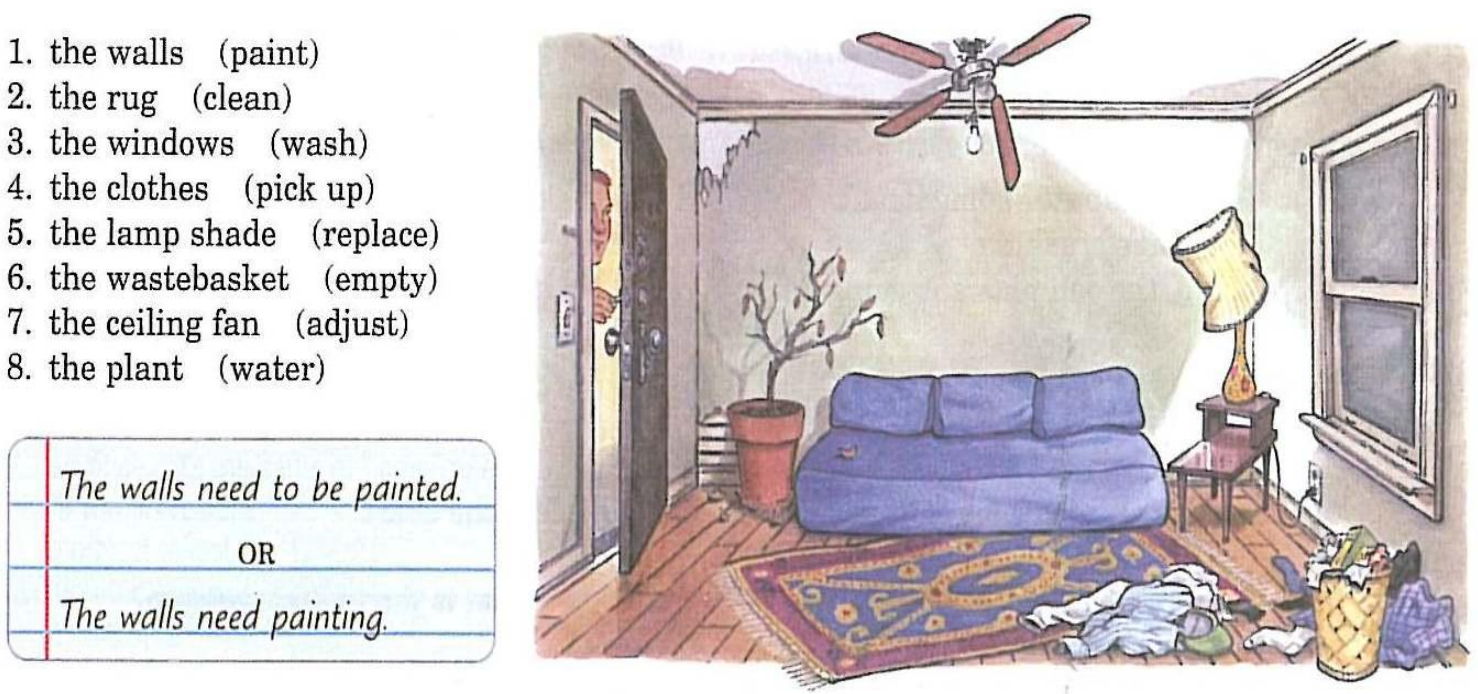

Figure 2. Example of non-decorative pictures (adopted from Interchange 3, p. 39) 
The above results also demonstrate some differences between the two textbooks. Top Notch $3 B$ has more photos, particularly color photos, than Interchange 3 (about three times). While Interchange 3 uses more drawings to display objects and interactions, Top Notch 3 uses more photos to show them. The high proportion of color photos can be regarded as a merit of Top Notch compared to other textbook because photos are similar to real-life situations and establish more authenticity. But it is possible that the higher percentage of high quality photos in Top Notch textbook have resulted in the higher price of this textbook-nearly 2.5 times more expensive than that of Interchange 3-putting financial pressure on some EFL learners. Besides, whether the strong appeal created by including many photos in Top Notch 3 translates directly into the language learning benefits is a moot question, which is due investigation, given that some students are less visually oriented. However, the fact that the Top Notch textbook has utilized more photos for objects and interactions than drawings can be an advantage in the sense that drawings seem to be more suitable for learners at lower L2 proficiency levels, perhaps not so much for learners at upper-intermediate levels for whom these textbooks are designed.

The results of the study also indicate that the majority of the portraits are (color) photos in the aforementioned textbooks. As Hill (2003) points out, one reason is the ease with which publishers can obtain from picture agencies. Also, the majority of actions are drawings presumably because the action situations required by authors of these textbooks might not have been available as photos, and possibly it was easier for publishers to have drawings. Moreover, portraits and actions have constituted the largest and smallest percentages of the categories, respectively, in the picture analysis. This finding may emphasize the above point about the practicality and the ease with which publisher should access sources; there may not be as many sources available for them to show actions as there are for portraits; capturing actions in static illustration might be difficult; perhaps the use of motion pictures such as videos is another option for the authors and publishers to rely on to show actions and speech acts in L2 learning environment.

\section{CONCLUSION}

We live in a visual society; advertising, films and media, in general, rely very strongly on the power of images and pictures (Tiemensma, 2009). The importance of using visual elements in textbooks has also been discussed in a body of research (Hill, 1990; Hill, 2003; Tiemensma, 2009; Wright \& Haleem, 1991). But little research has focused on the analysis of visuals in EFL textbooks. The current study evaluated visual elements in two EFL textbooks, that is, Interchange 3 and Top Notch 3B, taught commonly in foreign language schools in Iran. It focused on the balance of illustrations found in the above-mentioned textbooks and examined to what extent they were used for decorative purposes. The results obtained from the present study indicate that that these two textbooks utilize a high percentage of illustrations, with the focus on their facilitative effects in L2 learning. This is in line with today's trend in which most EFL textbooks move on from picture-free pages to range of materials full of stylish pictures. Moreover, Interchange 3 includes more drawings (for example to show objects and interactions) whereas Top Notch $3 B$ includes more photos than drawings. This can be a merit for the Top Notch textbook since the use of photos, particularly color ones, resembles everyday life situations and establishes authenticity especially for upperintermediate level students for whom these textbooks are designed. But this might result in its higher price and giving little 
space to presenting other modes of teaching materials. The results of the current study also indicate that the majority of the portraits are color photos in the whole data collected from both textbooks, and, further, actions are represented more through drawings, presumably because of practicality issues, i.e. the ease with which publishers can access them. Finally, the analysis of the pictures indicates that a small percentage of the pictures (including photos and drawings) are decorative in each of the textbooks, which is an advantage for the aforementioned textbooks; attempt has been made to make use of illustrations to enhance and facilitate L2 (i.e. English) learning through designing the above-mentioned textbooks.

\section{REFERENCES}

Allen, C. G. (2011). The effects of visual complexity on cognitive load as influenced by field dependency and spatial ability. Unpublished doctoral dissertation, New York University, US.

Ametller, J., \& Pinto, R. (2002). Students' reading of innovative images of energy at secondary school level.

International Journal of Science Education, 24(3), pp. 285-312.

Brand, Q. (1997). Art and art galleries: Resources for teachers. English Teaching Professional, 5, pp. 5-34.

Elo, S., \& Kyngas, H. (2008). The qualitative content analysis process. Journal of Advanced Nursing, 62(1), pp. 107-115.

Erfani, M. S. (2012). Pictures speak louder than words in ESP, too! English Language Teaching, 5(8), pp. 164-169.

Gerrard, E. E. (2008). Picturebooks as visual literacy: The influence of illustrations on second-graders, comprehension of narrative text. Unpublished master's thesis, University of Maryland, US.

Harmer, J. (2001). The practice of English language teaching. Harlow: Longman.
Hill, D. A. (1990). Visual impact. Harlow: Longman.

Hill, D. A. (2003). The visual elements in EFL coursebooks. In B. Tomlinson (Ed.), Developing materials for language teaching (pp. 174-182). London: Continuum Press.

Hutchinson, T., \& Torres, E. (1994). The textbook as agent of change. ELT Journal, 48(4), pp. 315-328.

Jahangard, A. (2007). Evaluation of EFL materials taught at Iranian public high schools. Asian EFL Journal, 9(2), pp. 130-150.

Levin, J. R. (1981). On functions of pictures in prose. In. F. J. Pirozzolo \& M. C. Wittrock (Eds.), Neuropsychological and cognitive processes in reading (pp. 203-228). New York: Academic Press.

Lohr, L. (2003). Creating graphics for learning and performance: Lessons in visual literacy. Upper Saddle River, NJ: Merrill.

McDonough, J., \& Shaw, C. (2003). Materials and methodology in ELT: A teacher's guide ( $2^{\text {nd }}$ ed.). Malden, MA: Blackwell Publishing.

Mukundan, J., Nimechisalem, V., \& Hajimohammadi, R. (2011). Developing an English language textbook evaluation checklist: A focus group study. International Journal of Humanities and Social Sciences, 1(2), pp. 100-106.

Peat, J. (2001). Health science research: A handbook of quantitative methods. Sydney: Allen \& Unwin.

Porcaro, J. W. (2001). Newspaper cartoons. Modern English Teacher, 10(2), pp. 29-33.

Richards, J. C. (2001). Curriculum development in language teaching. Cambridge: Cambridge University Press.

Richards, J. C., Hull, J., \& Proctor, S. (2005). Interchange 3: Teacher's edition ( $3^{\text {rd }}$ ed.). Cambridge: Cambridge University Press. 
Romney, C., \& Bell, L. (2012). The role of graphics in business English textbooks. In K. Bradford-Watts, R. Chartrand, \& E. Skier (Eds.), The 2011 Pan-SIG Conference Proceedings (pp. 210-219). Matsumoto: JALT.

Saslow, J., \& Ascher, A. (2006). Top notch 3B: English for today's world ( $2^{\text {nd }} \mathrm{ed}$.). New York: Pearson Longman.

Soars, J., \& Soars L. (1991). Headway preintermediate. Oxford: Oxford University Press.

Tiemensma, L. (2009). Visual literacy: To comics or not to comics? Promoting literacy using comics. Literacy and Reading and Information Literacy, 94. Retrieved 10 July from: http://www.ifla.org/annualconference/ifla75/index.html

Tomlinson, B. (Ed.) (2003). Developing materials for language teaching. London: Continuum Press.

Wright, A., \& Haleem, S. (1991). Visuals for the language classroom. Harlow: Longman. 